\title{
AN EXPERIMENTAC ANALYSIS OF ULTIMATUM BARGAINING
}

\author{
Werner GtiTH, Rolf SCHMITTBERGER and Bernd SCHWARZE*
}

Iniversita' - Köln, 5000 Köln 41, West Germany

Received Juiy 1982, final । ersion received January 1983

There are many experimental studies of bargaining behavior, but surprisingly enough nearly no attempt has been made to investigate the so-called ultimatum bargaining behavior experimentaliy. The special property of ultimatum bargaining games is that on every stage of the bargaining process only one player has to decide and that beiore the last stage the set of outcomes is already restricted to only two resulits. To make the ultimatum aspect obvious we concentrated on situations with two players and two stages. In the 'casy games' a given amount $c$ has to be distributed among the tho players, whereas in the 'complicated games' the players have to allocate a bundle of black and white chips with different values for both players. We performed two main experiments for easy games as well as for complicated games. By a specie! experiment it was investigated how the demands of subjects as player 1 are related to their asceptance decisions as player 2.

\section{Introduction}

A game in strategic or extensive form, which is played to solve a distribution problem, is called a bargaining game. Such a game has perfect information if all its information sets are singletons, i.e., there are no simultaneous decisions and every player is always completely informed about all the previous decisions. Consider a batgaining game with perfect information whose plays are all finite Such $\approx$ game is called an ultimatum bargaining game if the last decision of every play is to choose between two proderermined results. Often a game itself does not satisfy this definition, but contains subgames for which this is true.

In 2 -person bargaining one usually speaks of an ultimatum if one party can restrict the set of possible agreements to one single proposal which the other party can either accept or reject. Since in an ultimatum bargaining game the set of possible outcomes is narrowed down to only two results before the last deciaion is made, this explains our terminolc,gy.

Tho athors would like to thank Reinhard Selten (University of Bielefeld) and two mongmots reftrees for their valuable advice. 
The speciality of iltimatum bargaining gawes can be illustrated as follows: Sine the length of the play is bounded from rbove, there is always a player 3 who has to make the final decision. Now for all other players the game is over in the sense that they cannot infuence its outcrne nny longer. So all that player $i$ has to do is to make a choice which is good for himseif. We can say that player if fuds himself in a 1-person garne. Now consider a player I who makes his choice just before player $i$ erminues the game. If $j$ knows what player $i$ considers as good or bad, payer $j$ can easily predict how player $i$ will react. Thus in a certain sense we can say that player $j$, 100 , is ensaged in a l-person game. In the same way one can se that every player in an ultimatum bargaining game finds himself in a 1-person game. This shows that in ultimatum bargaining games strategic interaction occurs only in the form of anticipating future decisions. There is no rnutual interdependence resulting from simul aneous noves or ininite plays.

The obvious solution concept for ullinatum bargaining games is the subgame perfect equilibrium point [Selten (1975)]. The subgame perfect equilibrium behavior can be easily computed by first deternining the last decisions, ther the second last ones, etc. Most ultimatum bargaining games stave only one perfect equilibrium point. The delicate problem to select one of many equilibrium points as the solution of the game is of mily minor importance.

In the economic literature bargaining processes are often modelled as Wtimatum bargaining games [see, for instance. Stăh] (1972), and Krelle (1976)]. Here we do not discuss whether ultimatum bargaining garnes can acoquately represent real bargaining situations [see Harsanyi (1980), and Cuth (1979)]. We are mainly interested in ultimatum bargaining behavior because it allows one to analyse in detail certain aspects of bargaining behavior.

In any multistage bargaining process the parties have to anticipate future decisions. The specialty of ultimatum bargaining games is that these are the only strategic considerations and that especially the last decision is the most simple choice problem. The individually rational decision behavior will stherefore be rather obvious even if subjects do not have a strategic training. Dur experiments allow us to explore the following questions: Will subjects behave optimally? And if not why and in which direction will they deviate from their optimal decisions? Our approach is to investigate first the most simple bargaining models. Only when knowing what drives the individual decisions is simple games, one can be sure how to interpret the results of more complex situations. Our distinction of 'easy' and 'complicated' games is a suall strp in this direction. There are so many experimental studies of burg aining behuvior that we do not even try to give special zeferences; for inste rice, many of the 'Contributions to Experimental Economics', edited by A. sisuermann, deal with bargairing problems. But surprisingly enough, as fir as we know, nearly no experiments have been performed to analyse 
utimaum bargaining behavior. Because of thcir special structure ultimatum bargaining games are usef d to irvestigate experimentally how targainers anticipate the decision behavior of their opponents. This is especially true for games with only few players and rather short plays.

Consider a game which does not satisfy the definition of an ultimatum bargaiung gatne only because the players can choose betwen more than just two bargaining results at the last decision stage. Such a game will be called a bargaining game with ulimatum aspect [Güh (1976)]. Fouraker and Siegel (1963) have investigated the bargaining behavior in such games. In their interesting study they confronted their subjuts with a bilateral monopoly where first the seller states the price and ther. the bu/er determines $r$ is demand at this predetermined pice.

Fouraker and Siegel distinguish between compleur and incomplete information as well as single and repeated transaction experiments. We restrict our attention to single transaction experiments. It is obvious from the repeated prisoners' dilemma-experiments that a player will not completely exploit the ultimature aspect if he can be punished liter on. Furthermore, we can neglect the incomplete information experiments. Sirce the players do not know the types of their opponents, games with incomplete information do not satisfy the requirement of perfect information [Harsanyi (1968), and Selten (182)]. According to their data Fouraker and Siegel consider the subgame perfect equilibrium point $t .3$ be reasonably consistent with the observed bargaining behavior. In 11 of 20 experiments price and quantity were chosen exactly as prosicted by the equilibrium solution. Our data will indicate that this result will change if the pay.off distribution according to the equilibrium point is more extrene. Fourake and Siegel also vary this payoff distribution. Whereas in Experiment 2 the equilibrium payoly of the seller is much higher than the one of the buyer, these payoffs are equal in Experiment 1. For us it is a surprise that neve:theless the number of equilibrium results in Experiment 2 is only slightly smaller than in Experiment 1 . According to orr data subjects punish ar opponent, who exploits the ultimatum aspect, if this is not too co:tly for them.

It seems that the strategic asymmetry of both players was more acceptable in the experimen. of Fouraker and Siegel. This can be due to their special scenario. In highly industrialized countries most consuxer morkets are considered as seller markets. 'Buyers' therefore might be used to have less strategic power. In $y$ an abstract bargaining situation, where the brigaining parties have to diride a given amount of money, an asymmetri power relationship is prosably less accertable.

Another explanation is that subjects in the experiment: of Fouraker and Siege: could not sace each other. They might not even have been sure whether they actually face an opponent or a preprogrammed strategy. In our 
experiments all subjects cor ld see each other. But since bargaining pairs mere determined storhastically, none of them knew his opponent.

In the following we describe the scenario which was used to observe ultimatum bergaining behavior experimentally. Afterwards the data collected in the experiments will be discussed in detail and compared. In the coacluding section we stinmarize our main results and indicate some perspectives for the future study of ultimatum bargaining behavior.

\section{Deseription of experiments}

it is well-known in the economic literature [Selten (1978)] that subjects do not anticipate future decisions in the way which characterizes the individually rational decision behavior in ultimatum bargaining games. Players tend to neglect that there is a last stage which is so important for the normative solution. Thus it is more than doubtful whether the special structure of ultimatum bargaining garnes will be fully recognized if the bargaining process is more complicated in the sense that the number of stages is very large.

Now we are interested in ultimatum bargaining behavior since in these games strategic interaction occurs only in the form of anticipation. To make sure that all subjecks are aware of the special game situation, the easiest nontrivial ultimatum bargaining ganes with only two players and two decision stages have been used to test ultimatum bargining behavior.

The experiments can be partitioned into two subgroups: In one grom 1e two subjects have to determine only how to distribute a given amo:nt of money. These experiments will be callid 'easy games'. In the experiments of the second group they have to distribute certain amounts of black and white chips which do not have the same value for both of them. These experiments will be called complicated games'. Whereas the optimal decision behavior in easy games is obvious, complicated games require a slightly more thorough arialysis of the game situation. Comparing the results for easy and complicated games will show how the complexity of the game model influences bargaining results.

Before every experiment subjects were introduced to the bargaining situation in an informal way. The oral instructions were given according to the rules listed in the appendix. Each experiment consisted of several games which were played simultaneously. The group of $2 k$ sabjects was first subdivided by chance into two subgroups of equal size $k$. All subjects in one of the two subgroups were determined to be player 1 in the corresponding ultimatum game. They wene informed in dedvance that their opponeat will be chosen by chence out of the other subgroup. So no olayer 1 knew his opponent for sure. The 1 easy games differed only with respect to the 
amcint $c$ which was to be distributed among the two subjects. All experiments were games with complete information.

The number $k$ of games ranged from 9 to 12 . So the chances to meet a specific subject ats player 2 were rather low for all players 1 . All subjects were seated in the same room at desks which were far encugh from each other to exclude verbal communication. Furthermore, players 1 and players 2 were at opposite sides of the room. Each participant could sea all the others and had a complete control that the experinent was performed according to the instruction rules in the appendix. We did not observe attempts is exchange messages during the experiments. Beiween experiments communication was not restricted.

\subsection{Easy games}

In an easy ganis the two subjects were first determined to be player 1 and player 2. The subject chosen to be player 1 then declares which amount $a_{1}$ he claims for himself. The difference between the amount $c(>0)$, which can be distribuied, and $a_{1}$ is what player 1 wants to leave for player 2 . Given the decision of player 1 player 2 has to decide whether he accepts player 1's proposal or not. If 2 aicepts, player 1 gets $a_{1}$ and player 2 gets $c-a_{1}$. Dtherwise both players get zero.

Every subject in the subgroup of players 1 got a form (table 1) which informed him about the total amount $c$ to be distributed. Player 1 had to write down the amount of money $a_{1}$ which he demands for himself. Then the forms were collected and distributed by thance to the subjects in the other subgroup. Player 2 had to indicate whether he accepts the pro rosal of player 1 or not. Two tickets were attached to each form, one for player 1 and one for player 2. On each ticket there was a capital letter, indicating the game, and the player nuinber. So, for instance. $X_{1}$ is on the ticket of the subject who is player 1 in game $X$. We calied $X 1$ the sign of this subject. The subjects had to show their tickets to get their payoirs.

Table 1

The form given to subjects engaged in easy games.

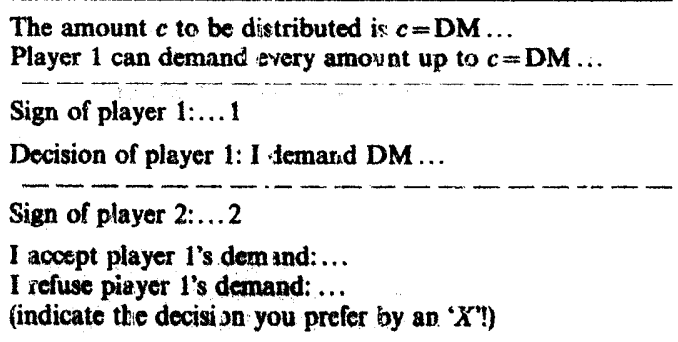


Let us shortly discuss the rationa! decision behavior in easy games. Indivisibility of money inplies that thare is a minimal positive amount $\varepsilon$ of money. Consider now an easy game: A rational player 2 will atways preftr the alternative which yields more for him and will clowese conflict only if this does not cost him anything. Thus the optimal decision for player 1 is to demand $c-\varepsilon$ for himsel and to leave the minimal positive amount $\varepsilon$ to player 2. This clearly illustrates the ultimatum aspect of easy games: 1 he decision of player 1 implies that player 2 can only axept his minimum or choose contlict.

\subsection{Complicated games}

The experimenis of complicated games were performed in a similar way. In a complicated game player 1 first has to divide a bundle of 5 black and 9 white chips. In order to do this player 1 determines a vector $\left(m_{1}, m_{2}\right)$ indicating the decision for one bundle (1) with $m_{1}(\leqq 5)$ blacl: and $m_{2}(\leqq 9)$ white chips and the complementary bundle (II) with $\left(5-i m_{1}\right)$ black and $\left(9-m_{2}\right)$ white chips. After the decision of player 1 player 2 has to decide whether he wints to have bundle (I) or bundle (II). The other bundle is given to player 1. Player 1 got DM 2 for each chip. Player 2 was paid DM 2 for a black chip ald DM 1 for a white chip. Both players were informed about these values.

The form given to the subjects engaged in a compicated game is shown in table 2. Again several exarnples were calculated to make sure that every subject completely understood the rules of the game. Some subjects had difficulties to learn how the distribution of chips determines the money payoffs.

In the complicater game the rational desion behavior is not so obvious. A rational player 2 will alwrys choose the bundle which yields a higher payoff for him. For player 1 it is evident thai he has to design bundles I and II such tha: the bundle, which player 2 will prefer, contains as few white

Table 2

The form given to subjects ergaged in complicated games.

Sign of player 1:... 1

Decision of player if Mayer 2 has to choose between

(1) ...blaci chkss and ... white chips (not more than 5 black and 9 white chips), or the remaining chips.

Sign of player $2 \ldots . .2$

Decisisn of player 2 :

If choce vector (l) of black and white chips...

II chorse the remaining vector of shiph (II)...

lindicate the decision you prefer by an $X \mathrm{X}$ ) 
chips as possible. Knowing this some easy calculations show that the optimal decision of player 1 is given by $\left(m_{1}, m_{2}\right)=(5,0)$ or $(0,9)$. This will induce player 2 to choose I in the first case ard II in the second case. The equilibrium payoff for player 1 is DM 18, whereas player 2 receives DM 10. If piayer 2 would deviate, he wo ld get DM 9 whereas player l's payoff would be DN 10 , i.e., a deviation of player 2 would cost player 1 much more than player 2 himself.

The coniplicated game is a well-known distribution procedure [see, ior instance, Kuhn (1978), Steinhaus (1948), Güth (1979)], often called 'the method of divide and choose'. In the economic literature it is mostiy applied to the problem of cutting cakes faily. In our example there are two different 'cakes' and two individuals with different preferences.

The method of divide and choose yields an envyfret allocation [Pazner and Sclimeidler (1974)] which is even Pareto-optinial in our special case. In general, this method determincs an allocation which is not Pareto-efficient [Güth (1976)]. Observe that a complicated game has other envyfree and Pareto-optimal allocations beside the voulibrium allocation. If player 2 receives the bundle $(5,1)$ of 5 black and 1 white chips and player 1 gets the residual bundle $(0,8)$, this allocation is also envyfree and Pareto-eficient. The same is true if player 2 receives the bundle $(5,2)$ and player ! the residual bundle $(0,7)$. All other Pareto-eff cient allocations are roi envyfree. Furthermore, the equilibrium payoff of player 1 is his maximal payoff in the set of envyfree allocations. This demonstrates that the method of divive and choose allows player 1 to exploit the preferences of player 2. Player 2 would prefer to be the one who determines two bundles I and II between which player 1 has to choose.

\section{Experimental results}

The subjects were graduate students of economics (University of Cologne) attending a seminar to get credit for the final exams. I is almost sure that none of the students vas familiar with game theory. Aft prilot studies in the summer semester of 1978 the main experiments $w_{i}{ }^{2}$ ? ourformed at the beginning of the next winter semester.

\section{s.1. Eas:'games}

For the sake of completeness we aiso show the results of the pilot experiment with easy games in table 3 . The results of one game, specified by a capital letter in column (1), appear in one line. The stcond colunn of table 3 gives the amount $c$ to be distributed. The third one the demand of player 1. A ' 1 ' in the fourth column indicates that player 2 accejted, whereas a ' 0 ' says that 2 refused player 1's proposal. Conflict resulterl in three (games C, G and $\mathrm{H}$ ) of the nine games in table 3. 
Table 3

Pilot study of caily games.

\begin{tabular}{|c|c|c|c|}
\hline Garne & $\begin{array}{l}c=\text { anount } \\
\text { to be } \\
\text { distributed } \\
\text { (DM) }\end{array}$ & $\begin{array}{l}\text { Denthind of } \\
\text { player } 1 \\
\text { (DM) }\end{array}$ & $\begin{array}{l}\text { Decision of } \\
\text { pleyer } 2\end{array}$ \\
\hline$A$ & 1 & 0.60 & 1 \\
\hline B & 1 & 060 & 1 \\
\hline c & 1 & 090 & 0 \\
\hline D & $i$ & 0.50 & 1 \\
\hline E & 1 & 0.50 & 1 \\
\hline$F$ & 1 & as1 & 1 \\
\hline$G$ & 1 & 1.00 & 0 \\
\hline II & 1 & 100 & 0 \\
\hline I & 1 & 0.50 & 1 \\
\hline
\end{tabular}

In the same way the results of the main experiments with easy gan es are given in tables 4 and 5. The experiments of easy games listed in table 4 were performed first. We refer to these results as unexperienced decision beliavior in easy games.

These experinents have been repeated after one week. Of course, a subject usually had to face a different amount $c$ to be distributed and to expect a different opponent. The results of the second experiment of easy games are given in tabie is we refer to thert as experienced decision behavior in easy games.

Tables 4 and 5 contain the resilts of 21 games each. In both tables there are three games with an amount $c=4 ; 5 ; 6 ; \ldots ; 10 \mathrm{DM}$. According to the unexperienced slocision behavior contlict seems to be rather exceptional (it results in only two of the 21 garaes) Since in table 5 there are 6 cases of conflict, the total amount paid te the subjects is lower in table 5 (DM 116) than in table 4 (DM 137).

Une could th to explain the grcater frequency of conflict according to the experienced behuriot by an increase of the average demand of players 1 . The a verage demand of players 1 is DM 4.38 in table 4 and 4.75 in table 5 . But the average demiand of pinyers 1 is a rather rough measure for the demand behavior of plajers 1 since it neglests the variation in the total amount $c$ to be dissributed A certain absolute increase of player 1's demand is more significunt if onity DM 4 on be distributed than in the case of DM 10. Gapirically it is apt trus that pleyor 2 ahoys chocses the altemative which yields a higher peyot, The deciliou behavior of players 1 slso depends on

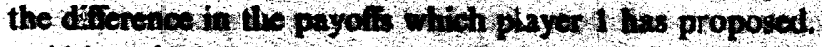

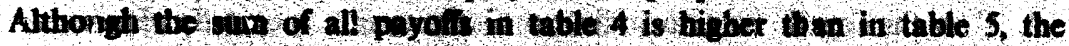



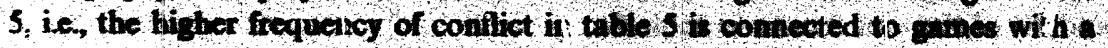


Table 4

Naive docision behavior in eesy games.

\begin{tabular}{|c|c|c|c|}
\hline Game & $\begin{array}{l}\text { c account } \\
\text { to be } \\
\text { distributed } \\
\text { (DM) }\end{array}$ & $\begin{array}{l}\text { Demand of } \\
\text { player } 1 \\
\text { (DM) }\end{array}$ & $\begin{array}{l}\text { Decision of } \\
\text { player } 2\end{array}$ \\
\hline A & 10 & 6.00 & 1 \\
\hline B & 9 & 8.00 & 1 \\
\hline C & 8 & 4.00 & 1 \\
\hline D & 4 & 2.00 & 1 \\
\hline $\mathbf{E}$ & 5 & 3.50 & 1 \\
\hline F & 6 & 3.00 & $!$ \\
\hline $\mathbf{G}$ & 7 & 3.50 & $\mathbf{i}$ \\
\hline H & 10 & 5.00 & 1 \\
\hline$I$ & 10 & 5.00 & 1 \\
\hline J & 9 & 5.00 & 1 \\
\hline K & 9 & 5.55 & 1 \\
\hline L & 8 & 4.35 & 1 \\
\hline $\mathbf{M}$ & 8 & 5.00 & 1 \\
\hline $\mathbf{N}$ & 7 & 5.00 & 1 \\
\hline 0 & 7 & 5.85 & 1 \\
\hline $\mathbf{P}$ & 6 & 4.00 & 1 \\
\hline$Q$ & 6 & 4.80 & 0 \\
\hline $\mathbf{R}$ & 5 & 2.50 & 1 \\
\hline $\mathbf{S}$ & 5 & 3.00 & 1 \\
\hline $\mathbf{T}$ & 4 & 4.00 & 0 \\
\hline $\mathrm{U}$ & 4 & 4.00 & 1 \\
\hline
\end{tabular}

Table !

Experienced decision behavior in asy games.

\begin{tabular}{|c|c|c|c|}
\hline Game & $\begin{array}{l}c=\text { amount } \\
\text { to be } \\
\text { distributed } \\
\text { (DM) }\end{array}$ & $\begin{array}{l}\text { Deriand of } \\
\text { pla's: } \\
\text { (DNi) }\end{array}$ & $\begin{array}{l}\text { Decision of } \\
\text { player } 2\end{array}$ \\
\hline A & 10 & 7.00 & 1 \\
\hline B & 10 & 7.50 & 1 \\
\hline C & 9 & 4.50 & 1 \\
\hline D & 9 & 6.00 & $i$ \\
\hline E & 8 & 5.00 & 1 \\
\hline F & 8 & 7.00 & $i$ \\
\hline G & 7 & 4.00 & 1 \\
\hline $\mathrm{H}$ & 7 & 5.00 & $i$ \\
\hline 1 & 4 & 3.00 & 0 \\
\hline J & 4 & 3.00 & 0 \\
\hline $\mathbf{K}$ & 5 & 4.99 & 0 \\
\hline $\mathbf{I}$ & 5 & 3.00 & 1 \\
\hline $\mathbf{M}$ & 6 & 500 & 0 \\
\hline iN & 6 & 3.80 & 1 \\
\hline 0 & 10 & 6.00 & 1 \\
\hline p & 9 & 4.50 & 1 \\
\hline Q & 8 & 6.50 & 1 \\
\hline $\mathbf{R}$ & 7 & 4.00 & 0 \\
\hline S & 6 & 3.00 & 1 \\
\hline$T$ & 5 & 4.00 & 0 \\
\hline $\mathbf{U}$ & 4 & 3.00 & 1 \\
\hline
\end{tabular}


relativaly tow amount $c$ to be distributad. The avarage payoff of players 1 not engeged in contict is DM $438 \mathrm{MM}$ 5.05) in table 4 (5), wherens for players 2 it is DM $2.83(\mathrm{DM} 268)$

Altogether one gets the Ifiprescion thet in the bocond experiment players 1 wre more daring than in the lirst one. This caused on one side a higher frequency of confict and on the other tide a highet payoff of those players 1 whose more ambitious demands vere nevertheless socepted by their opponents.

One can try to explain the variation of the demands, i,e, the demand belavior of players 1 in easy games, by the variation of the amounts $c$ to be distributed. To do this we calculated bow the following three hypotheses:

$$
\begin{aligned}
& a_{1}^{1}=\alpha c+\beta \\
& a_{1}^{\prime}=\alpha c^{\prime}, \\
& a_{1}^{\prime}=\alpha c^{\alpha}
\end{aligned}
$$

can explain the demand bebavior of plavers 1 in table 4 as well as in table 5 . The results are listed in table 6 whose first column gives the fenctional form (1), (2) or (3) of the hypothesis. In the second and third column appear the values of the parameters $\alpha$ and $\beta$ for table $4(5)$ denoted by $\alpha_{4}\left(\alpha_{5}\right)$ and $\beta_{2}$ $\left(\beta_{3}\right)$ respectively. The correlation cocficient $r_{4}^{2}$ and $r_{5}^{2}$ for tables 4 and 5 in the fourth coivmn of table 6 indicate how mak of the variation of players 1's demands can be explained by the variation of $c$. It can be exen that the nonlinear hypotheses yieid better explanations in both cases and, furthermcre, that all bypotheses yield bater recults for the experieneed demand behav or of table 5 . Of course, the resulls shoult be condidered more as an illuatration of playns 1 's demunds and not as a valid statistical analysis sirice there are lot enough data avilable.

The acceptance behavior of players 2 listed in table 4 (5) is visualized in fig 1 (2) Siece playe 2 has only the choice to acopt (indicated by '1') or to reflave findicated by 0 ) a diven demaed of player 1 , his payof $c-a_{1}$ in cise of acceptancs le, for $a_{2}=1$, is of pecial interest. This amount can be

\begin{tabular}{|c|c|c|c|c|c|c|}
\hline Hoplines & 4 & (a) & A. & $(8)$ & 4 & (1) \\
\hline$a-n+1$ & aso & asca & 120 & (asi7) & 002 & (0.630) \\
\hline$a_{1}-\omega^{2}$ & 100 & ase & 0.71 & 0029 & 2511 & (26so) \\
\hline$x=0$ & 197 & $(A)$ & oul & p.121) & ost1 & $(0,53)$ \\
\hline
\end{tabular}

$$
\text { tonto }
$$




regarded as the costs of player 2 for choosing conflict. The decision of player 2 may also depend on the share $\left(c-a_{1}\right) / c$ of player 2 according to player 1 's proposal. One would expect that playe. 2 is more likely to refuse a given demand of player 1 if his payoff $\left(c-a_{1}\right)$ as well as his share $\left(c-a_{1}\right) / c$ in case of acceptance are comparatively low. Beside one exceptional case (player R2 in table 5) where the rather moderate denand $a_{1}=D M 4$ was refused at costs of DM 3 for player 2 , it can be seen with the help of figs. 1 and 2 that the experimental results are in line with our intuitive expectations.

\subsection{Consistency of dzmands in easy games}

After testing twice the behavior in easy games vve became interested to learn how the demand behavior of a subject, i.e., his decisions as player 1 , is related to his acceptance behavior, i.e., his decisions as player 2 [similar questions for other game situations are analysed by Stone (1958)]. Would a certain subject accept as player 2 an ofler to distribute $c$ which he would suggest as player 1 ? In order to investigate this question, we performed a third experiment of the easy game with $c==7 \mathrm{DM}$ in the following way: All of the 37 subjects participated in the experiment as player 1 as well as player 2. First every subject had to decide as player 1 which amount $a_{1}$ he demands

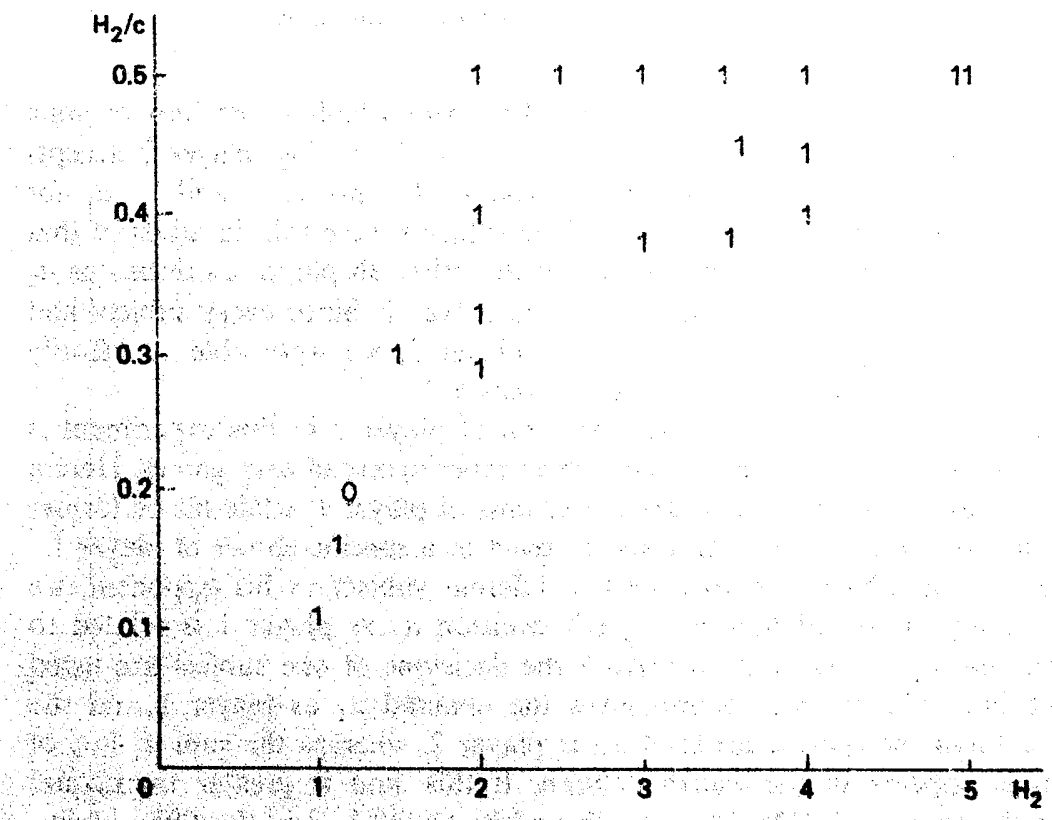

Fis 1. Naive accoptance behavior in easy games. 


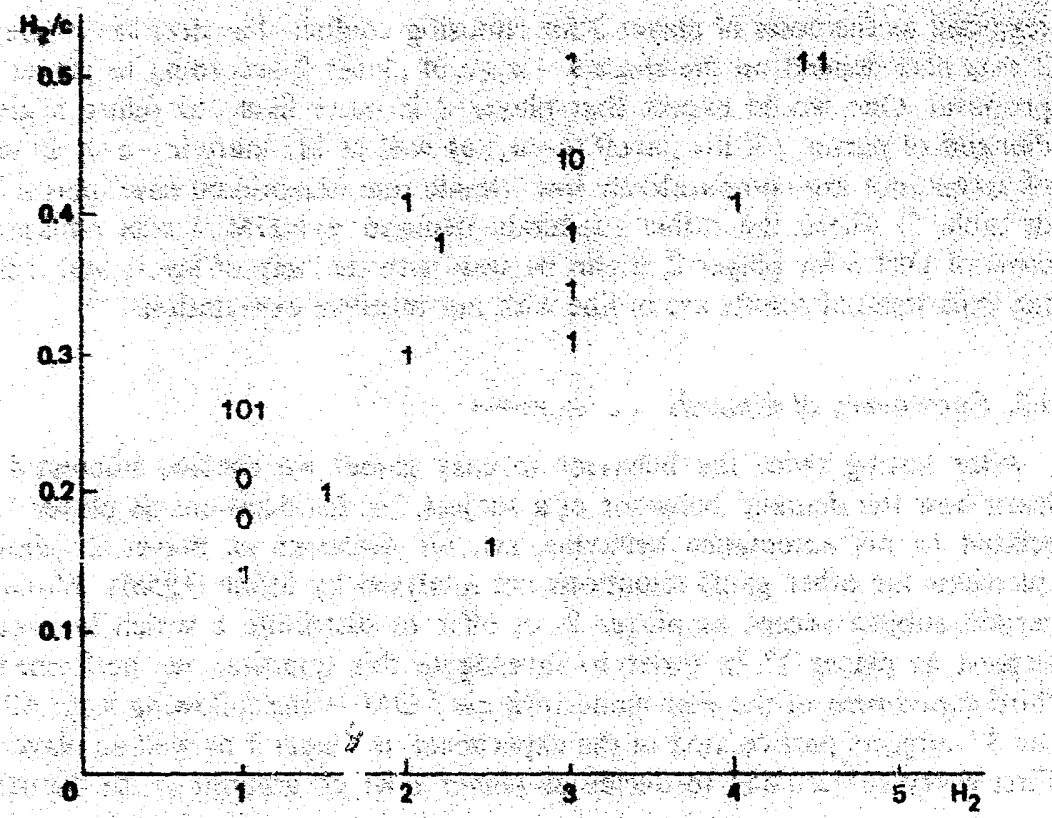

Fig 2 Experienced soceplance behavior in easy games.

for hirself. Then cvery subject got another form which asted him to stzte his minimal acceptance payoff $a_{2}$ as player 2 If $c-a_{1} \geq a_{2}$, player 2 accepts player is demand which yields the payof $a_{1}$ for player and $c-a_{1}$ for player 2 Conflict results if $c-a_{1}<a_{2}$. The subjects were told in advanoe that it will be deterwined by chence which of the other 36 player 2 s decisions $a_{2}$ will be opposed to the own decision a as player 1 . Since every subject had to kand in his sign as player 1 and as player 2 , we were able to identify uniquely his decisions as player 1 and as phyer 2 .

It should be mentioned that the decision of player 2 in this experinent is more complieted compared to the formet experiments of easy games. Here a



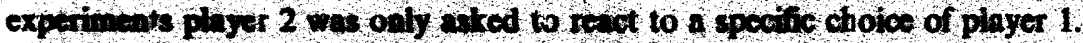

Althouh a wijoct bed to expet a dilloreat subjoes as his opponent, we

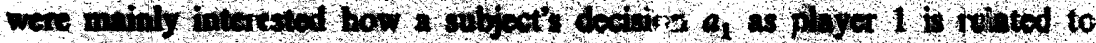
his docition a of ploger 2 In toble 7 the decisions of abe subject are listed



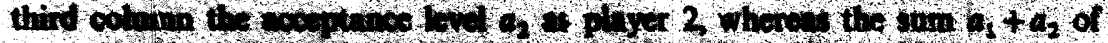

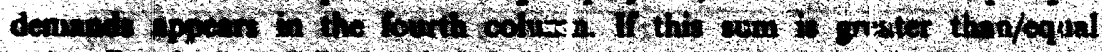

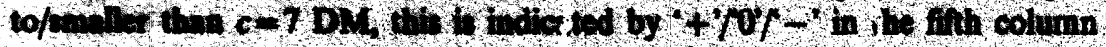
of tabis 7 
Table 7

Consiatency of payof demunds in easy games.

\begin{tabular}{|c|c|c|c|c|}
\hline $\begin{array}{l}\text { Index of } \\
\text { ubject }\end{array}$ & $\begin{array}{l}a_{1} \text { - deatand } \\
\text { a player } 1\end{array}$ & $\begin{array}{l}a_{2}=\text { demand } \\
\text { as player } 2\end{array}$ & $\begin{array}{l}a_{1}+a_{2}=\text { sum } \\
\text { of demands }\end{array}$ & $\begin{array}{l}\text { Consistency } \\
\text { of demunds }\end{array}$ \\
\hline 1 & 4.00 & 3.00 & 7.00 & 0 \\
\hline 2 & 3.50 & 2.50 & 6.00 & - \\
\hline 3 & 3.50 & 3.50 & 7.00 & 0 \\
\hline 4 & 3.50 & 3.50 & 7.00 & 0 \\
\hline 5 & 400 & 3.00 & 7.00 & 0 \\
\hline 6 & 3.50 & 3.50 & 7.06 & 0 \\
\hline 7 & 4.00 & 3.00 & 7.00 & 0 \\
\hline 8 & 5.00 & 3.50 & 8.50 & + \\
\hline 9 & 3.50 & 3.50 & 7.00 & 0 \\
\hline 10 & 3.50 & 3.50 & 7.00 & 0 \\
\hline 11 & 3.50 & 3.50 & 7.00 & 0 \\
\hline 12. & 3.50 & 2.00 & 5.50 & - \\
\hline 13 & 5.00 & 1.00 & 6.00 & - \\
\hline 14 & 3.50 & 1.00 & 4.50 & - \\
\hline 15 & 3.50 & 5.00 & 8.50 & + \\
\hline 16 & 4.01 & 2.50 & 6.50 & - \\
\hline 17 & 400 & 3.00 & 7.00 & 0 \\
\hline 18 & $4.00^{\circ}$ & 3.00 & 7.00 & 0 \\
\hline 19 & 5.00 & 1.00 & 6.00 & $\cdots$ \\
\hline 20 & 6.99 & 0.01 & 7.00 & 0 \\
\hline 21 & 3.50 & 2.00 & 5.50 & - \\
\hline 22 & 4.00 & 2.50 & 6.50 & - \\
\hline 23 & 4.00 & 3.50 & 7.50 & + \\
\hline 24 & 3.50 & 3.00 & 6.50 & - \\
\hline 25 & 5,00 & 2.00 & 7.00 & 0 \\
\hline 26 & 4.00 & 1.00 & 5.00 & - \\
\hline 27 & 3.50 & 2.00 & 5.50 & $\ldots$ \\
\hline 28 & 4.00 & 1.00 & 5.00 & - \\
\hline 29 & 3.50 & 3.00 & 6.50 & - \\
\hline 30 & 3.50 & 2.50 & 6.00 & $\ldots$ \\
\hline 31 & 4.50 & 3.50 & 8.00 & + \\
\hline 32 & 400 & 3.00 & 7.00 & 0 \\
\hline 33 & 400 & 0.10 & 4.10 & $\cdots$ \\
\hline 34 & 3.50 & 3.50 & 7.00 & 1 \\
\hline 35 & 4.00 & 1.00 & 5.00 & - \\
\hline 36 & 7.00 & 3.50 & 10.50 & + \\
\hline 37 & 4.00 & 250 & 6.50 & - \\
\hline
\end{tabular}

5 decision vectors are in conflict $(+), 15$ consistent $(0)$ and 17 in anticonflict $(-)$. Thus 32 of the 37 subjects revealed a mudest demand behavior in tite sease that the payoff $c-a_{1}$ was not smalk. than their acoeptance level $a_{2}$ os player 2 Nearly half of the 37 vectors $\left(a_{1}, a_{2}\right)$ were even in anticonflict These subjicts were willing to accept demands of player 1 which were higher than their tyn aspiration levels $a_{1}$.

In case of conflict subjocts leave less to player 2 than they themselves are willing to accept as player 2 . They must consider themselves as exceptionally 
tough or ambitious since otherwise they would have to expect conflict. The subject in the 15th row of tabte 7 probablo misunderstood the situation.

In case that $\left(a_{1}, a_{2}\right)$ is consistent, the subject leaves as piayer 1 to player 2 exactly what he is just willing to aciopt is player 2 Sich a subject reveals that he considers the payoff vector $\left(a_{1}, a_{2}\right)$ as the obvious outcome. So, for instance, in 7 of the 15 cases of consistency the equal split (3.50 DM; 3.50 DM) is proposed. In the other consistent pairs subjects asked as players 1 for more than as players 2 which indicates their attempt to exploit the ultimatum aspect.

The average share $a_{1} / c$ demanded by players 1 is only $55 \%$ in table 7 compared to $64.9 \%$ in table 4 and $61 \% \%$ in table 5 , i.e., in the consistency test players 1 were more modest than in the former experiments. This can be explained by the fact that in the consistency test subjocts had to decide as player 1 and as player 2. Knowing to be player 1 in one game and player 2 in another game, might have caused some subjects to care for a fair bargaining result. Of course, a rational decision maker would not allow his decision in one game to depend on his choice in another game. But one cannot expect in real life that players are able atd willing to distinguish so clearly betwren the decisios in one game and the cne in another game situation.

\subsection{Cominticated games}

In the pilot study with complicated games the payoffs were one tenth of the payol is as given in tine description of the game. In the second column of cable 8 is the bundle $I=\left(m_{1}, m_{2}\right)$ as designed by player 1 . The third column gives the payof vector $\mathrm{H}(\mathrm{I})=\left(\mathrm{H}_{1}\left(\mathrm{I}_{2} \mathrm{H}_{2}(\mathrm{I})\right.\right.$ which results if player 2 chooses bundle I for himself, whrreas the payoff vector $H(I)=\left(H_{1}(\mathrm{II}), H_{2}(\mathrm{II})\right)$ for the choice of bundle $I=\left(f-m_{1}, 9-m_{2}\right)$ by player 2 appears in the fourth

Table 8

Pilot tudy of corapticted games.

\begin{tabular}{|c|c|c|c|c|}
\hline Game & $\begin{array}{l}\text { Decision } \\
I=\left(z n_{1}, m_{2}\right) \\
\text { of player } 1\end{array}$ & $\underset{(\mathrm{DM})}{\left(\mathrm{H}_{1} \mathbf{M}\right)}\left(\mathrm{H}_{2}(\mathbf{D})\right.$ & $\begin{array}{l}\left(\mathrm{H}_{1}(\mathrm{II}), \mathrm{H}_{2}(\mathrm{II})\right. \\
\text { (DM) }\end{array}$ & $\begin{array}{l}\text { Decision of } \\
\text { playex } 2\end{array}$ \\
\hline $\begin{array}{l}\mathbf{A} \\
\mathbf{C} \\
\mathbf{D} \\
\mathbf{E} \\
\mathbf{F} \\
\mathbf{G} \\
\mathbf{H} \\
\mathbf{D}\end{array}$ & $\begin{array}{l}(3,5) \\
(5,2) \\
(3,1) \\
(2,0) \\
(4,3) \\
(5,0),\end{array}$ & nom & 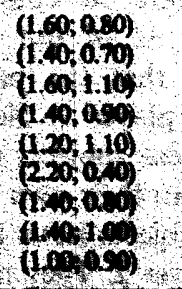 & $\begin{array}{l}\mathbf{1} \\
\mathbf{1} \\
\mathbf{1} \\
\mathbf{1} \\
\mathbf{1} \\
\mathbf{I} \\
\mathbf{n} \\
\mathbf{1}\end{array}$ \\
\hline
\end{tabular}


column of table 8 . The actual choice I or II of player 2 is listed in the last column of table 8 . It can be seen from table 8 that players 2 alvjays chose the bundle which yielded a higher ayoff $\mathrm{H}_{2}$. In the pilot study of complicated games only one player 1, veinely subject 11, proposed the equilibriam solution.

The same subjects who participated in the main experiments of easy games were afterwards confronted with the complicated game. The results of the main experiments with the complicated game are listed in tables 9 and 10. In a first test the payoffs were the same as in the pilot study. The esults of this first test are listed in table 9; we refer to them as decision behavior in conplicated games with low payoffs. After one week the experiment was repiated with the rather high payoffs as deternired by the description of the game. These results - we refer to them as decision behavior in complicated games with high payoffs - are listed in table 10.

Compared to an easy game situation the equilibrium payof vector $(1.80$ $\mathrm{DM} ; 1.00 \mathrm{DM})$ in table 9 or $(18 \mathrm{DM} ; 10 \mathrm{DM})$ in table 10 is less extreme in complicated games since it yields comparatively high pavoffs for both players. There are two possibilities $I=\left(m_{1}, m_{2}\right)$ for player 1 to suggest the rational solution, namely $\left(m_{1}, m_{2}\right)=(5,0)$ and $\left(m_{1}, m_{2}\right)=(0,9)$. In 6 of the 17 games in table 9 players 1 suggested the rational solution, whereas in table 10 this was done in 9 of 15 games. Thus compared to our results for easy games players 1 in complicated games rely more often on the rational decision behavior although it is more difficult to derive. This indicates that

Table 9

Irecision behavior in complicated games with low payoffs.




Take 0

Decision behavior in complicated gutus with bigh puyofs.

\begin{tabular}{|c|c|c|c|c|}
\hline Game & $\begin{array}{l}\text { Jecision } \\
=\left(m_{1}, m_{2}\right) \\
\text { : player }\end{array}$ & $\begin{array}{l}\left(H_{1}(D) H_{2}(\mathrm{M})\right. \\
(\mathrm{BM})\end{array}$ & $\begin{array}{l}\left(\mathrm{H}_{3}(\mathrm{H}) ; \mathrm{W}_{2}(\mathrm{AH})\right. \\
\mathrm{DMM}\end{array}$ & $\begin{array}{l}\text { Decision of } \\
\text { player? }\end{array}$ \\
\hline A & 5,0 & $(19 ; 10)$ & (10. 9$\}$ & 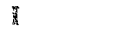 \\
\hline 3 & $(5,1)$ & $(16 ; 1)$ & $(12 ; 8)$ & $i$ \\
\hline$c$ & S 1$)$ & $(15: 11)$ & $(12 ; 8)$ & I \\
\hline$D$ & $5,9)$ & $18: 10$ & $10 ; 9$ & il \\
\hline $\mathrm{E}$ & $(5,0)$ & $118: 2010$ & $(10 ; 9)$ & $\Gamma$ \\
\hline$\vec{F}$ & 5,01 & $(18 ; 10)$ & $(10 ; 9)$ & 1 \\
\hline$G$ & 5,0 & $(18 ; 10)$ & $(10 ; 9)$ & 1 \\
\hline $\mathrm{H}$ & 3,4 & $14 ; 10)$ & (it: 9) & \\
\hline $\mathbf{I}$ & $(5,0)$ & $8 ; 10$ & $(10 ; 3)$ & 1 \\
\hline$J$ & $5,0)$ & $(18 ; 10)$ & $(10 ; 9)$ & 1 \\
\hline 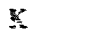 & $4,1\}$ & $(18 ; 9)$ & $(10: 10)$ & 1 \\
\hline $\mathcal{L}$ & $(4,1)$ & $(18 ; 9)$ & $(10 ; 10)$ & II \\
\hline$M$ & $(1,8)$ & $(10 ; 10)$ & $(18 ; 9)$ & 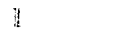 \\
\hline $\mathrm{N}$ & $\{0,9\}$ & $\{10 ; 9\}$ & $(18 ; 10)$ & Bi \\
\hline 0 & $(5,0)$ & $(18 ; 10)$ & $(10 ; 9)$ & II \\
\hline
\end{tabular}

subjects did not deviate from the optimal behavio because of their difficulties in solving the game. The main reason seems to be that the ratuonal solution is not contidered as socially acceptable or fair.

In one of their bilateral roonopoly experiments Fotraker and Siegel (1963) have an equilibrium payon vector which is comparable to the one of complicated games. In the sther experiments the equilibrium payofis of both players are equai. Although we, too, observed a strong tendency to behave optimaliy in complicated games, the results of Fouraker and Siegel favor even more the normative solution. It secms fair to say that this is probabiy due to the greater acceptability of the equilibrium payof distribution in their experiments. As already indicated in the Introduction, the different results of Fouraker and Siegel may be related to the special scenario which they have used.

In one of the six (four of the nine) games of table $9(10)$ in which player 1 suggested the rational solution, player 2 did not accept this, i.e., player 2 chose the bunile which implied lower payofis for both players. The results for easy games showed already that players 2 are willing to suffer a monetary loss if they oonsider th demand of player 1 as unacceptable. Now if only player 2 deviates from the rational solution, he himself cuffers a loss of DM 0.10 (table 9) ar DM 1 (table 10), whereas player l's loss is DM 0.80 or DM 8. Since on the or her side of the equilibrium payof vector (DM 1.80; DM 1) or (DM 18; DM 10) yields a considerably higher payoff to player 1 , it is no surprise that sometimes players 2 chose the bundle which implies lower payols for both players. If player 2 is not willing, to accept the payoff vector 
implied by the nomative solution, he can cause a payofi vector with much nore balanced individual payoffs at relatively $6 \%$ costs by deviating from the rational solution.

Although the number of ganes in table 10 is smaller than in table 9 , the rational solution has been suggested more often by players 1 . On one side this tendency sowards rationality can be explained by the fact that the subjects were more famillar with complicated games in the repeazed experiment. On the other side payolfs in table 10 are much higher than those of table 9. This wight have caused some players 1 to consider their decisions more carefully.

If player 1 wants an equal split, he can propose this either by $:=(4,4)$ or the corresponding bundie II or by $I=(4,1)$ and the corresponding bundle II. If player 2 accepts the equal split, the payoff vector is (DM 12: DM 12) in the first case and (DM 10, DM 10) in the second one. In both cases it pays for player 2 to accept the equal split; if he devates player 2 would suffer a loss while player 1 would gain by such a deviation. In is, of course, better to design $\left(m_{1}, m_{2}\right)=(1,5)$ or the corresponding bundle (4) 4) since this implies higher payoffs for both players.

In table 9 only one player 1 suggesis an equa'. split, namely the one with high payof's, whereas in table 10 three players : suggest the equal split with low payoffs. This indicates that in the repeated experi nent there is a stronger tendency to suggest an equal split and that not all players $I$ in the repeated experiment were fully aware of the payoff structure. At least for these players 1 it is doubtfal whether they have analysed the game situation carefully enough.

In a complicated game player 1 chooses a maximin-strategy if he designs a bundle $I=\left(m_{1}, m_{2}\right)$ with $m_{1}+m_{2}=7$. Due to the special structure of complicated games the choice of a maximin-strategy by player 1 determines uniquely the payoff of player 1 (DM 1.40 in table 9 and DM 14 in table 10). In table 9 five players 1 chose a maximin-strategy, in table 10 this occurs only once. Thus comapared to the repeated experiment pliayers 1 in the first experiment seemed to be more risk averse.

Altogether one can say that in the second experiment of complicated games more players 1 tended towards the normative solution while more players 2 were willing to block unbalanced payoff vectors. This behavior of players 2 has its counterpart in a stronger tendency of some experierced players 1 to design bundles which allow more balanced payoff vectors.

\section{Conclasions}

Ultimatum bargaining games are special bargaining ganes since interaction of players occurs only in the form of anticipation. In order to make the ultimatum aspect obvious, we concentrated on the easiest non- 
trivial ultinatum barganing games with two players and two decision stages. In easy ganes where a given amount $c$ has to be distributed the normative solution is extrene in the sense that the player who has to decide on the second stage gets only the smallest possible positive payof. Onr exporimental resuits show that in actual life the ultimatum aspect of easy games will not have such extreme consequences: Independent of the game form, subjects often rely on what they consider a thr or justiffed result Furthermore, the ulinaturn aspect cannot be compingly exploited since subjects to not hesitate to punish if their opponent ask' for 'too much'.

The typical consideration of a player 2 in an easy game seems to be as follows: 'If player I left a fair amount to me, I will accept. If not and if I do not sacrifice too much, I will punish him by choosing conflict.' Correspondingly, a player 1 typically will argue like: I have to leave at leasi an amount $c-a_{1}$ for player 2 so that he will consider the costs of choosing confici as too high.' One therefore should expect that the relation of playe: 1's to player 2's payoff will increase if the amount $c$ increases. To estimate the exact functional form of this relationship, one should perform more experiments of easy games with various amounts $c$. Especially, one should try to include situations with very high amounts $c$, for instance $c=100 \mathrm{DM}$. It is, of course, very expensive to rerform experiments with such high values of $c$. To deal with high amounts $c$ one might consider experiments where one determines by chance $k^{\prime}(<k)$ out of the $k$ simultaneous games whose payofis are actually paid. Subjects would face higher amounts $c$ wr ch they can distribute with positive probavility although the sum of payofis in all $k$ grmes can be even lower than in our experiments.

Another way to perforn experiments with higher amounts $c$, is to auction the positions of payer 1 and player 2. Some subjects would bid for the position of play 1 in a given easy game, others for the position of player 2 . According 10 , the procedure used by Guth and Schwarze (1983) the position is sold to ihe highest bidder at the price of the second highest hid. Then the winners of the two independent auctions finally play the game. The payoffs would be their payoffs in the easy game minus the price of their position. A part from its lower costs this procedure provides new explanatory variables and avoids tendencies toward egalitarien payoff distributions. If the positions are assizned to subjects by chance or arbitrarily, the more fortunate subjects often are reluctant to exploit their 'unjustified' strategic advantages. But if a piayer had to compete for his position and to pay for it, he might not hesitate to exploit its strategic possibilities.

The consistency test was performed for only one easy game. It would be interesting to study how the results are influenced if the subjects have to face very high amounts $c$ to be distributed One would expect that the nunber of decision vectors $\left(a_{1}, a_{2}\right)$ in conflict will decrease because conflict would imply

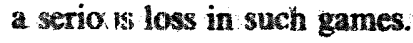


For complicated games it was shown that they are speciai exarnples for the method of divide and choose which is clamed to yield fair divisions. This indicates that the ultimatum aspect of complicated games is less obvious. As a matter of fact the normetive solution of such games is envyfree in the sense of Pazner and Schmeidler (1974). Our results how a clear tend ncy of players 1 to exploit the ultimatum aspect of surh a bargaining si uation. Although several subjects tried to cause balanced payoff vectors, the tendency toward the normative solution with unbalanced payofs we: muct stronger.

Uitimatum bargaining gares are standard examples to demonstrate how poorly the characteristic function reflects the strategic possibilities [Güth (1978)]. The characteristic function of an easy game is, for instance, completely symmetric in spite of piayer l's strategic advantage. Thar is why cooperative solution concepts are not very informative. They either consider all efficient and individually rational payoff distributions of easy gaines as stable or prescribe the equal split as the unique solution. Our resultiv show that efficiency does not hold in general. There are cases of conflic: in easy games and non-eficient agreements in complicated games. Obviously some subjects tried to cause egalitarian payoff distritutions. But there was a much stronger tendency to exploit the ultimatum aspect. Cooperative game theory is therefore of only little help when explairing ultimatum bargaining behavior.

In easy games all possible strategies of player 1 are maximin-stiategies. For player 2 the equilibrium strategy is also a maximin-strategy. For cornplicated games the equilibrium strategy of jlayer 2 is also a maximinstrategy. But tor player 1 the situation is difierent in complicated games. Here a maximin-strategy of player 1 requires that both bundles contain 7 chips. In 5 of 17 complicated games with low payoffs we observed that player

did choose a maximin-strategy. In the case of high payoffs only 1 of 15 players has chosen a maximin-strategy. This shows that the tendency to $\therefore$ oid any risk is of only minor importancs, especially for experienced subjects.

\section{Appendix: Instruction rules}

\section{A.1. Instruction rules for easy games}

You will be faced with a simpie bargaining problem with only two bargainers, plsyer 1 and player 2 . In each bargaining yame both players have to distribute $a$ wiven amount $c=D M \ldots$ among thenselves. The rules of the baigaining g?me are as follows:

First player $\left\{\right.$ can determine any mount $a_{1}=\mathrm{DM} \ldots$ between 0 and $c$ which 
he demands for himsoli The difference $c-a_{1}$ is what player 1 offers to player 2.

Player 2 will bo informed about player 1 's decision $a_{1}$. Knowing player 1 s proposal player 2 can either accept this proposal or choose conflict.

If player 2 acoopts player 1 s proposal, player 1 gets $a_{2}$ and player 2 the residual amount c- $a_{1}$. In case of conflict both players get zero.

(IIlustration of bargaining rules by various numerical examples). The experimient will proceed as follows:

There will be $k=\ldots$ bargaining games with different amousts $c$ to bc distributed. First it vill be decided by chance who of you will be players 1 and who of you will be players 2 in the $k$ bargaining games. All players 1 will be seated at the (solated) desks on one side, whereas players 2 will be seated at the (isolated) deiks on the other side of the toom.

Each player 1 will receive a decision form which informs him about the amount $c$ to be distributed. This is also the maximal amount player 1 can ask for. Every player 1 has to fill in bis decision $a_{*}$. When determining his decision $a_{1}$, play 1 low not know who of the $k=\ldots$ players 2 will be his cpponent.

After all players 1 have made their decision their decision forms are distributed by chance among the $k=\ldots$ players 2 . Knowing the amount $r$ to be distributed and player 1 's demand $a_{1}$ each player 2 has to decide whether he accepts the payof proposal $\left(a_{1}, c-a_{1}\right)$ of player 1 or not.

Each player has 10 minutes for tis decision. When al decisions bave been made, the decision forms vill be collected. As described above the payofis are $a_{1}=\mathrm{DM}$.. For player 1 and $c-a_{1}-\mathrm{DM}$. for player 2 if player 2 accepts the proposal $\left(a_{1}, c-a_{1}\right)$ Otherwise buth players receive DM 0 . To get your money you have to keep the ticket which is attached to your decision form.

If you have any questions, we will be happy to answer then now. During the experiment it is forbidden to ask questions or to make remarks.

\section{A.2. Instruction rules for complicated games (with high payofs)}

You will be faced with a simple bargaining problem with only two bargairen, player 1 and player 2 In each bargaining game both players have to distribute a bundlit of 5 black and 9 white chips ameng themselves. Player 1 will gt DM 2 for ench chip. Play or 2 wit be paid EM 2 for a black chip and DM I for a white ond The rules of the bargaining gane are as follows:

First pla yer 1 can determine a bundle $\left(m_{1}, m_{2}\right)$ of $m_{1}$ black and $m_{2}$ white chips wh $g \leq m_{1} \leq 5$ and $0 \leq m_{2} \leq 9$. 
Player 2 will be taformed about player l's decision $\left(m_{1}, m_{2}\right)$. Knowing player I's decision $\left(m_{1}, m_{2}\right)$ player 2 can chrsose between the bundle $\left(m_{1}, m_{2}\right)$ of $m_{1}$ black and $m_{2}$ white chips or the residual biundle $\left(5-m_{1}, 9-m_{2}\right)$ with $5-m_{1}$ black and $9-m_{2}$ white chips. Player 1 receives the bundle which has not been chosen by player 2 .

The payof of each player is determined by the vilur of all the chips which he received. If, for instance, player 2 chooses the bundle $\left(m_{1}, m_{2}\right)$, his payoff is $m_{1} \cdot$ DM 2 $+m_{2}$. DM 1. Player 2's payoff is DM 2 times the number of chips which he received.

(1lustration of bargaining rules by various numerical examples). The experiment will proceed as follows:

Thers will be $k=\ldots$ bargaining games. First it will be decided by chance who of you will be players 1 and who of you will be players 2 in the $k$ bargaining games. All players 1 will be seated at the (isolated) desks on one side, whereas players 2 . will be seated at the (isolated) desks on the other side of the room.

Each player 1 will receive a decision forin. Every player 1 has to determine a bundle $I=\left(m_{1}, m_{2}\right)$ of $m_{1}$ black and $m_{2}$ white chips. By this he ofers player 2 to choose between the bundle $I=\left(m_{1}, m_{2}\right)$ and the residual bundle $I I=$ $\left(5-m_{1}, 9-m_{2}\right)$ of $5-m_{1}$ black and $9-m_{2}$ white chips. When de ermining his decision $I=\left(m_{1}, m_{2}\right)$, player 1 does not know who of the $k=\ldots$ l layers 2 will be his opponent.

After all players 1 have made their decision, their decision forms are distributed by chance among the $k=\ldots$ piayers 2 . Knowing the two bundles $I=\left(m_{1}, m_{2}\right)$ and $I I=\left(5-m_{1}, 9-m_{2}\right)$ each player 2 has to decids: whether he wants the bundle $I=\left(m_{1}, m_{2}\right)$ or the bundle $I I=\left(5-m_{1}, 9-m_{2}\right)$.

Each player has 15 minutes for his decision. When all decisions have been made, the decision forms will be collected. As described abov: your payoff will be determined by the bundle of black and white chips which you received. To get your money you have $t>$ keep the tickec which is attached to your Jecision form.

If you have any questions, we will be happy to answer them now. During the experiment it is forbidden to ask questions or to make remarks.

\section{References}

Fouraker, L.E. and S. Siegel, 195:1, Bargaining hehavior (New York).

Güth, $W_{.6}$ 1976, Toward a more general study of v. Stackelberg-situations, Zetschrift für die Gesamie Staak wissenschaft 132, 592-608.

Gätb, W., 1978, Zur Theorie kollektiver Lohnverhandl:ngen (Baden-Baden). 


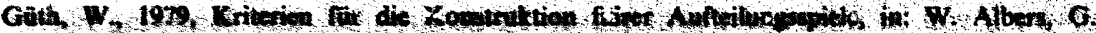

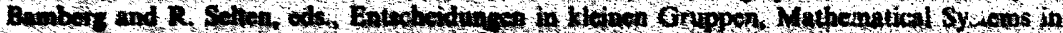
Bcowem 4 , $57-65$

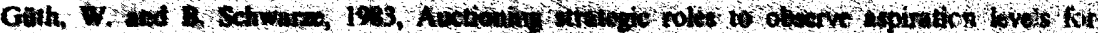

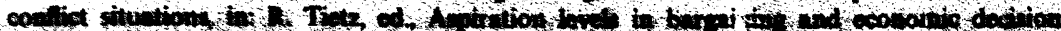

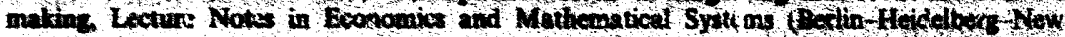
Yort).

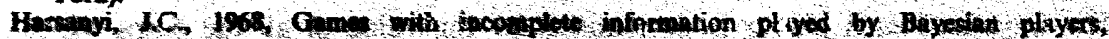



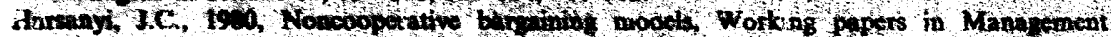

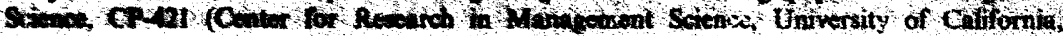
Burteley, (A).

Krelle, W., 1976, Preisthooric, Part 11, Ch 9.4 (Tubingen).

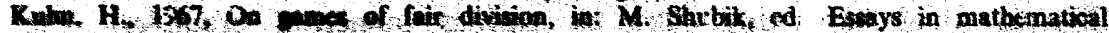

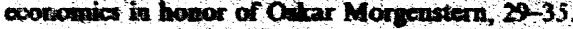

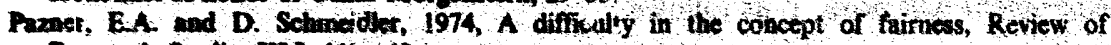
Economic Studio XI $44[-1 \leqslant 3$.

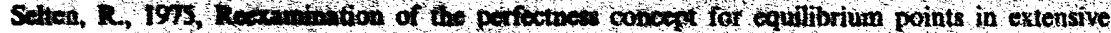

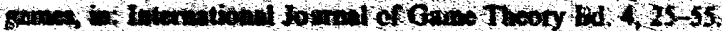



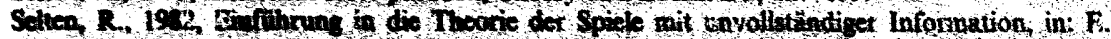

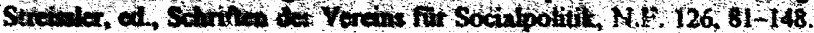

Sthl, J. 1972 Barointane theory (Stockhohm).

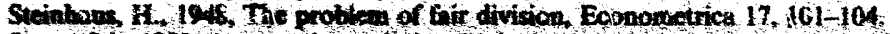

Stone, JU, 1958, An etgrivent it betpaining gines, Econometrict 26, 286-296. 